\title{
Guimarães Rocha (ou Glauber Rosa)
}

Por Jair Tadeu da

Fonseca

\section{Resumo}

Este ensaio visa abordar o "romance" Riverão Sussuarana, de Glauber Rocha, em que o autor e Guimarães Rosa se tornam personagens. A neobarroca linguagem de excessos que constitui a narrativa apresenta uma escrita de exceção, até mesmo uma neografia, ou heterografia, de caráter alegórico, como desafio à ortografia e como afirmação autográfica de uma autoria fantasmagórica.

\section{Palavras-chave}

Neobarroco, neografia, Glauber Rocha, Guimarães Rosa.

\begin{abstract}
This essay aims at approaching Glauber Rocha's "novel" Riverão Sussuarana, in which the author and Guimarães Rosa become characters. The neobaroque language of excesses, that constitutes the narrative, presents an exceptive writing, even an allegorical neography, or heterography, as a challenge to orthography and as autographic affirmation of a phantasmagoric authorship.
\end{abstract}

\section{Keywords}

Neobaroque, neography, Glauber Rocha, Guimarães Rosa. 
Podem ser feitas aproximações entre aspectos da obra cinematográfica de Glauber Rocha e a obra literária de Guimarães Rosa, a qual inspirou Deus e o Diabo na Terra do Sol (1964), junto aos livros de Euclides da Cunha, José Lins do Rego e Jorge Amado, além do romanceiro e das cantorias populares da tradição oral nordestina e dos westerns de John Ford. Mas há uma importante referência explícita a Rosa em uma vertente menos conhecida da obra de Glauber, que é a da escrita. Em 1978, o cineasta lançou Riverão Sussuarana, que ele às vezes chamou de romance, mas, como o próprio autor explica em entrevista, seu texto extrapola os limites do que se convencionou serem as obras reunidas sob essa rubrica de gênero: "O livro é ao mesmo tempo um manifesto literário e estético. A teoria e a prática daquele livro são transferidas para a música, para o cinema, qualquer tipo de arte. (...) Incorpora uma espécie de renovela, de desnovela, de recordel." (ROCHA, 1981, 351).

Os neologismos criados por Glauber - "renovela" e "desnovela" - indicam o renovar e o desfazer da novela, enquanto "recordel" remete a uma retomada do cordel, talvez também ao nome da editora que publicou o livro - Record - e certamente à recordação. Riverão Sussuarana é marcado pelo memorialismo e pela autobiografia, além de se referir explicitamente a Guimarães Rosa e aludir a James Joyce, desde o título, que alude ao "Liso do Suçuarão" de Grande sertão: veredas e ao "riverrun" de Finnegans Wake. Morte, velório, luto e ressurreição balizam tanto a "desnovela" de Glauber quanto o texto de Joyce, marcado que é pela circularidade, pelo fluxo temporal do corso-ricorso de Giambattista Vico e pelo rio Liffey, que corta a cidade de Dublim e é alegorizado pela figura mutante de Anna Livia Plurabelle. A palavra "riverrun", com que começa Finnegans Wake, transformou-se no "riveräo" de Glauber, que, além de manter correspondência sonora com o termo original, contempla a idéia da recorrência temporal e espacial, de fluxo, de circularidade, de ciclo: riverão, provável corruptela de ribeirão, é uma palavra-valise que, contendo river (rio) e verão (estação do ano e futuro do verbo ver), sintetiza o espaço e o tempo em movimento. Esse riveráo solicita uma travessia alucinatória porque é por sua vez um eixo mágico que atravessa os territórios do real. Quanto ao papel do rio e de suas margens na geografia literária de Grande sertão: veredas, escreve Antonio Candido:

Desdobremos bem o mapa. Como um largo couro de boi, o Norte de Minas se alastra, cortado no fio do lombo pelo São Francisco, - acidente físico e realidade mágica, curso d'água e deus fluvial, eixo do Sertão.

"Rio é só o São Francisco, o Rio do Chico. O resto pequeno é vereda. E algum ribeirão".

"O São Francisco partiu minha vida em duas partes." (...)

Nas águas do Rio, eixo líquido, dá-se o encontro com o Menino, com Diadorim menino, que marcaria toda a vida do narrador (...) (CANDIDO, 1978, 124-125).

1 No mesmo ensaio, Candido refere-se à "lagoa Sussuarana, que os mapas registram". (CANDIDO, 1978, p.126). É importante lembrar que sussuarana, além de dar título a uma canção popular, de Heckel Tavares e Luiz Peixoto, citada no livro de Glauber, é o nome de uma pequena onça, o que permite relacionar o texto do cineasta e escritor baiano, marcado pela metamorfose, ao conto "Meu Tio, o lauaretê", de Guimarães Rosa. A referência ao conto é clara, ao final de Riveräo Sussuarana. 
No livro de Glauber, em que o Rio seria uma metáfora da vida e do próprio texto, a referência geográfica também é o São Francisco, que, ultrapassando fronteiras, atravessa o território brasileiro de Minas ao Nordeste, constituindo-se, por sua vez, em uma outra espécie de "fronteira móvel", que é como o narrador caracteriza as Entradas e Bandeiras. (ROCHA, 1978, 85). Os tropos fluviais, junto a outras metáforas sertanejas, também são usados quando, em uma entrevista, Glauber apresenta a relação de seu livro com os de Guimarães Rosa.

Em Riverão, tentei falar literariamente sobre o sertão brasileiro que faz parte de minha vida pessoal, mas através de uma nova visão, por isso é que no livro eu parto do próprio Guimarães Rosa como escritor para proceder através dele a uma reanálise, uma revisita dessa região, procurando sobretudo a integração de individualidade e sociedade. Guimarães foi meu guia e, ao mesmo tempo, o mito a ser desmistificado. Eu me coloco como o jagunço que vai escrever um livro e pede licença ao latifundiário, o coronel Guimarães Rosa. O jagunço quer contar algumas histórias que se passam perto daquele sertão, como se fosse um pequeno afluente daquele grande rio que ele descreveu. (ROCHA. In: REZENDE, 1986, 148).

Glauber aborda, com a ironia de sua falsa modéstia, a influência recebida, por seu afluente ribeirão, do "grande rio" de Rosa, apontando o dado biográfico, em sua relação com o social, como fatores que justificariam seu interesse pelo sertão e por Grande sertão: veredas, cujo autor é personagem de Riverão Sussuarana. O livro começa com a narração dos contatos de Glauber com o escritor mineiro e reproduz, em sua primeira página, a dedicatória do romancista ao então jornalista e cineasta principiante, datada de 1962, em um exemplar de Primeiras estórias, "dedicaligrafado". (ROCHA, 1978, 9). Glauber também narra seu encontro pessoal com Rosa, em Gênova, em 1965, durante a Resenha do Cinema Latino-Americano, ocorrida no congresso intitulado Terceiro Mundo e Comunidade Mundial, em que apresentou a sua "Estética da Fome”, texto fundamental e de grande repercussão, na Mesa Redonda sobre o Cinema Novo Brasileiro, aberta com uma comunicação de Antonio Candido. $O$ cineasta confere à descrição que faz do escritor mineiro uma sensualidade que caracterizará sua personagem em Riverão Sussuarana:

Em janeiro de 1965 voei Los Angeles Milão escrevendo a tese "Estetyca da Fome" pro "I CONGRESSO DO TERCEYRO MUNDO" em Genova e conheci Guimarães Rosa, alto, meio careca, forte, gravata borboleta, óculos, fala fina, de singularminbiguidade macho/feme, delicado, vermelhão, sensual, namoradeiro cantando Izabella Campos no corredor do Hotel chamou atrizes e jornalistas brazyleyras também algumas recepcionistas italianas pracompanhá-lo em compras por Roma sorrindo: "Agora Guimarães Rosa Vai dormir. Está cansado". (ROCHA, 1978, 10). [sic]

Riverão Sussuarana (Rivo, Riverim, River, Riverun, Riveran, Sussu, Adeodato) é um dos muitos nomes do protagonista da "renovela", um jagunço, cuja estória é relatada ao Major e Mestre Rosa, "Embaixador Romancista", pela personagem de Glauber Rocha, um "Cine Repórter", cujo nome também toma formas diversas. É chamado de 
Glôbe, Grobe, Glaubiru, Grober, Glaudi, seu Roxo, até que perto do fim da "desnovela" funde-se com o "Embaixador Romancista" na personagem de Guimarães Rocha, para logo depois se tornar Jango Rosa, e ao final desmembrar-se de novo em dois. A viagem que fazem pelo sertão - que poderíamos caracterizar como lisérgica, por mudar de forma e rumo a todo instante -, acompanhados pelo Comandante e por sua suposta filha, Linda, leva-os a enveredar-se pela estória narrada por Glauber, conduzindo-os ao encontro de Riverão. Este se apaixona por Linda, a qual é filha de Diadorim com Riobaldo, como é revelado, no início do livro, logo após ela "transar" com o Major Rosa. Este, mesmo depois de morto, estará destinado, junto a Riverão, a lutar pela destruição do empresário transnacional Karter Bracker, personificação alegórica do ocupante estrangeiro, que invadiu as terras do sertão e mantém o povo como escravo nas minas de urânio, as quais controla, mancomunadỏ com o Senador Lima Ferraz, para tentar descobrir o "Geo Fogo", que estaria no "Geo Center".

Muito gerais, essas linhas não são um modo de tentar parafrasear o livro, tarefa praticamente impossível, mas de escolher alguns pontos sobre os quais situar, de modo sucinto, alguns elementos de um texto que é um verdadeiro desafio à narrativa. Esta se constrói e se desconstrói a cada passo, na mudança de registro e de estilo, em um esbanjamento neobarroco da linguagem necessária a uma imaginação desenfreada e que não conhece censura - o que confere ao texto uma dimensão escatológica, nos dois sentidos, e uma violência verbal pouco comuns na literatura brasileira. Trata-se de submeter a língua a uma violência que rompe a velha dicotomia de forma e conteúdo. Em Riverão, o excesso de linguagem corresponde à linguagem de excesso, que, ao dar conta, por exemplo, do erotismo de exceção, apresenta uma escrita erótica e estilisticamente polimorfa. Com isso, temos uma constante mudança de referenciais, que faz 0 narrador transtrocar-se com outras personagens, como vimos em relação a "Guimarães Rocha”, e como pode ser constatado no seguinte trecho, que trata de um jagunço sanguinário, Angelo Mauro, também Anjo Mauro:

O coronel foi decente $\mathrm{e}$ Angelo beijou sua velha mão, agradecia quem the criou, virei o corpo de lado mas a coxadoeu espremendo o revólver virou e viu a porta semi-aberta, luz morrendo mansa pela telha de vidro em cima duma compoteira com doce de caju deu vontade, Anjo se levantei, abriu a tampa azulada do vidro-cristal, meteu as unhas sujas, mastigo, bebeu água e fumo cigarro de palha (...). (ROCHA, 1978, 32)

O movimento da terceira pessoa para a primeira, em uma seqüência de eventos narrativos que, aparentemente, é a mesma, vividos supostamente por uma mesma personagem, faz ver, pela metamorfose, que "eu é um outro", segundo a fórmula de Rimbaud, como se o narrador, em sua performance verbal, fosse um diretor de cena, que representa o papel da personagem a ser desempenhado por outro, revezando-se com este. A descontinuidade, que marca os filmes de Glauber e também os eventos de sua trajetória existencial, artística e política, é uma característica de Riverão Sussuarana, e pode ser percebida desde o nível dos detalhes, como o exemplificado acima, até o modo geral como se estrutura e se desestrutura a narrativa. O continuum do "riverão" é marcado pela descontinuidade, pois, embora o livro não seja dividido em capítulos, seu curso é interrompido e desviado de diversas maneiras, para continuar fluindo imediata- 


\section{ITha de Santa Catarina}

mente, como o rio de Heráclito, que é sempre o mesmo, mas sempre outro. Em alguns momentos do texto, este abandona sua vertente rosiana-joyciana para assumir um estilo faulkneriano, como é perceptível nas seqüências relativas à "Cidade das Cruzes", em que a narrativa acompanha a ação de pistoleiros e suas vítimas, de dentro da tocaia e também do ponto de vista do tocaiado. (ROCHA, 1978, 167-178). A respeito do escritor americano, Glauber afirma em um depoimento:

Gosto muito de Faulkner, porque há sempre nele uma acumulação simultânea e progressiva dos conflitos. Por outro lado, o meio social, os negros, a gente do Sul, isto poderia ser também o Nordeste do Brasil, ou algum pais da América Latina. Existe aliás um romance de Faulkner que eu quero filmar, é The Wild Palms. (ROCHA, 1981, 92).

Como nos romances de Faulkner, em que o espaço "gótico" do Sul dos Estados Unidos corresponde ao conturbado mundo interior das personagens nele configuradas, em Glauber é tênue a fronteira entre o mundo de sensações, pensamentos e palavras das personagens envolvidas na ação criminosa e o sertão que surge, nesse caso, como cenário de um "nordestern" sombrio. A seqüência, que se segue imediatamente a essas de que tratamos, situa-se em Jardim das Pyranhas, cidade (fictícia) do filme que Glauber lançou em 1969, O Dragão da Maldade contra o Santo Guerreiro, lugar situado na fronteira entre o arcaico e o moderno, a memória e a região, e entre a região e as ficções capazes de transfigurá-la, sendo uma delas a do western.

Assim, a corrente de Riverão Sussuarana é cambiante por ser formada por tipos diversos de textos, como o testemunho, o diálogo dramático, o poema, a alegoria filosófica, alinhavados por uma prosa poética e de fiç̧ão em constante mutação formal, que alude a outros textos e chega a incorporar em seu fluxo dois contos atribuídos à irmã do autor, Anecy Rocha: "Para meu marido" e "Assassynato". Ao definir seu "recordel", Glauber afirma: "É um livro do Terceiro Mundo. E ao mesmo tempo, a história sangrenta de minha gente, de minha família." (ROCHA. In: REZENDE, 1986, 152). As fronteiras móveis de Riverão permitem, a Glauber, justapor o geral e o particular e tornar pública, em seu "romance", sua história privada e familiar, como ocorre em relação à morte da irmã, morte que, segundo o autor-narrador-personagem, "arrebentou a estrutura de 'Riverão Sussuarana'." (ROCHA, 1978, 214). A partir desse ponto, interrompe-se a narrativa que podemos considerar meta-regionalista e inicia-se uma dolorosa narrativa "policial", e confessional, em que Glauber acusa o cunhado, o cineasta Walter Lima Júnior, de ter assassinado Anecy, que caíra no poço do elevador do prédio onde morava. Aos poucos, retoma-se e conclui-se a travessia narrativa, em que não falta a auto-reflexáo, apesar do caos de que parece emergir.

A metáfora tem caras, eu não estava Louko como falavam meus amigos e a imprensa glosava em Manchetes, Artigos, Entrevistas: "GLAUBER ROCHA LOUKO DECLARA GUIMARAES ROSA MORREU NO SERTÃO LUTANDO CONTRA TROPAS NORTE AMERICANAS INVADIRAM CIDADES FENYCYAS DO PYAUY E SUA IRMÄ ANECY ROCHA FOI CULTURALMENTE ASSASSINADA PELO MACHISMO SÁDICO DOS INTELECTUAYS LYBERAYS (.... $)^{n}$ o discurso barroco contraditório a dialeticantropofagica do corpus brazyliensis em particular, o Eu Selvagem consciente do 
Ocupante, o Ocupado que se ocupa do Ocupante e não de $\mathrm{Si}$, o Ser seqüestrado colonial de Frantz Fanon, o discurso flagelado da Eztetyca da Fome na Tragedya Kolonyal, a comunicação de massas através dà Heuztorya Sekreta e Publyka da Cyvylyzação e da Barbárie (...). (ROCHA, 1978, 279.280).

Há uma tensão, na obra de Glauber, surgida de sua ânsia de pensar contra a razão do "ocupante", tendo sido formado por ela, negando ou sabotando os recursos de que tem que se valer nessa luta ideológica, na qual encarna o dilaceramento dos intelectuais da cultura e da terra ocupadas, condenados a pensar com as "cabeças cortadas", obrigados a inventar outras formas de pensamento, outras linguagens. Essa necessidade, nascida da falta, da fome de formas, e do excesso, da deglutição de formas, passou a exigir uma outra escrita, até mesmo uma neografia, de exceção, que surge como um desafio à gramática normativa, à ortografia. Esse jogo da diferença - täo caro aos modernistas $\mathrm{e}$, antes, aos simbolistas - é talvez manobra compensatória frente à impossibilidade de criação de uma língua que expresse uma alternativa de pensar. É importante lembrar que, a partir de meados da década de 1970, Glauber criou uma neografia, ou uma heterografia, que é também autográfica, usada inclusive em seus textos jornalísticos: em determinadas palavras escolbidas, ele grafa $y$ no lugar de $i, k$ em vez de $c$, e substitui $s$ por $z$. Junto às maiúsculas alegorizantes, esse recurso permite que se veja o texto como alegoria desde a visualidade do significante, como em um cinema mudo das letras. Ao defender a linguagem de seu livro, o cineasta afirma:

Não é o português culto, o português da burguesia, mas um português violentado e inspirado permanentemente pelo português selvagem, que brota do meu inconsciente. Eu escrevo sem nenhum racionalismo e a novidade está aí. Se eu fosse escrever igual a Machado de Assis, o livro teria o interesse de mais uma reportagem sobre o sertäo. (...) 0 que interessa, pelo menos para mim, é que o livro é a versão literária de Glauber Rocha sobre o sertão. É o meu falar, é como eu sinto. (ROCHA. In: REZENDE, 1986, 145-146).

Se a linguagem literária de Rosa já realiza a devoração e deglutição criativas dos falares populares e de línguas estrangeiras, a apropriação que a escrita de Glauber faz dela, com seu "falar", é antropofágica, canibalesca e calibanesca. Neste caso, a referência é Caliban, o selvagem escravizado de A tempestade (1612), de Shakespeare, que faz uso próprio da língua do mestre, convertendo esse meio de dominação em instrumento de revolta, e torna-se símbolo literário e cultural, já no século XIX, ou personificação alegórica das lutas de libertação na América Latina e na África, no século XX. (RETAMAR, 1988). Não se trata de razão, desrazão ou loucura, em Riverão, mas do dilacerante conflito entre elas, sempre presente em Glauber. Por um lado, abdicar da razão, porque seria uma das armas dos colonizadores, pode justificar sua posição de "donos da razão" e confirmar o lugar por eles reservado aos supostamente desprovidos da razão, os colonizados, que, além disso, ainda ficam sem terra e sem cultura própria. Por outro lado, abandonar a razão colonizadora significaria demonstrar que ela é um instrumento de barbárie, de desrazão e loucura, não de civilização e sanidade, e que a razão dos donos da terra pode não ser a mesma dos "danados" ou "condenados da terra", ou não 


\section{ITha de Santa Catarina}

deveria ser. O logos é lugar de uma agonística, assim como a terra é espaço de disputa.

Ao falar de seu projeto de escrita de Riverão, Glauber relembra a conversa que teve com o tradutor americano de seus roteiros e afirma: "Sempre tentado a escrever romances teóricos falei com Mike que Walter Benjamyn grandintelectual judeu suicidouse amedrontado dos Nazystaz numa fronteira da Segunda Guerra Mundial (...)" (ROCHA, 1978, 13). Com isso, o autor-narrador-personagem inaugura uma série de referências à travessia de fronteiras, às passagens que balizam seu "romance teórico", entre as quais, aquela em que surge, pela primeira vez, seu protagonista: "O jagunço Riverão Sussuarana cruzava a Fronteyra Bahia Mynaz pra pedir proteção na fazenda do Coronel Dermeraveldo de Olyveyra." (ROCHA, 1978, 14). A partir dessa fronteira geográfica, necessária para situar a região que caracteriza a obra de Guimarães Rosa e o sertão das memórias da infância de Glauber e da sua família, rememora-se a história das "Revoluções fracassadas" do Brasil, em que se remonta à ocupação do território: "A fronteira móvel das Entradas e Bandeyras sob a lei da escravidão negra, índia... uma raça se formando... subdesenvolvimento advindo do desenvolvimento (...)" (ROCHA, 1978, 85). Da história colonial à neocolonial, passa-se a um estágio fundamental para a compreensão do país - 0 do mito -, que permitiria a ultrapassagem dos limites da razão colonizadora, quando "Riverão e Luiz Papagayo desceram do Mapa nas fronteiras míticas" (ROCHA, 1978, 105). Próximo ao fim da "renovela", após ter colaborado heroicamente, junto a Riverão, para que os flagelados sertanejos, tornados escravos, se libertassem e matassem Karter Bracker, Guimarães Rosa desaparece, com todas as personagens de Riverão Sussuarana, antes que pudessem ser presas pelo exército, pois "Rosa sabia das verdadeiras fronteiras e desenrolou das coxas mapa na sua pele (...)" (ROCHA, 1978, 281).

De modo geral, o livro recebeu críticas ligeiras, porém implacáveis, na imprensa, e também a indiferença da crítica universitária, com exceção de uma resenha de Antônio Carlos Miguel, de 1979, e de um texto redigido por Alexandre Eulalio, publicado inicialmente em Leia Livros, em 1978, no qual são apontados a "arbitrariedade de calígrafo" com que Glauber exerce a escrita e os excessos de sua "enumeração caótica que ambiciona respiração cósmica". (EULALIO, 1993, 300 e 301). Apesar de se referir ao que considera defeituoso no livro, quando afirma que 0 autor tropeça na "simulação de pretensa liberdade sem limites", o que resultaria em "inúteis encompridamentos e repetições supérfluas" (EULALIO, 1993, 300), o crítico soube compreender a importância desse livro difícil, soube ler muito bem algo considerado ilegível. De modo elegante, Eulalio aponta um certo desleixo de Glauber na fatura de Riverão, mas esses "inúteis encompridamentos e repetições supérfluas", tidos como defeitos, são justamente algumas das marcas da obra do cineasta, como um todo, a qual poderíamos considerar neobarroca, tanto nos textos, quanto nos filmes. Assim, o livro eleva ao quadrado o barroquismo que caracteriza a obra de Rosa, mas de forma paroxística, imperfeita, áspera e exasperante. Bem ao contrário da perfectibilidade, do bom acabamento, da suavidade $\mathrm{e}$ do equilibrio que temos nos textos do escritor mineiro. Enquanto Rosa revisa, corrige e reescreve suas narrativas, o texto de Rocha resiste à revisão e recusa a correção, pois não admite o certo e o errado na escrita.

Eulalio define Riverão Sussuarana como "peregrinação ao encontro dos próprios fantasmas, em que o autor cavalga grande sertão adentro na companhia de um João Guimarães Rosa redivivo." (EULALIO, 1993, 299). De fato, toda a atmosfera criada pelo texto de Glauber é fantasmática e suas personagens alegóricas são fantasmagóricas, 
principalmente a de Guimarães Rosa, com sua presença-ausência fundamental. A partir da "morte do autor", nada pode deter seu retorno como fantasma, o qual ainda nos assombra desde os textos da literatura e da cultura. Escreve Augusto Meyer, antes dessa anunciada morte enunciada: "Assim nasce a projeção desse fantasma - o autor - no tempo. Ele era mais do que ele mesmo, era toda sua família espiritual em marcha para o futuro. Às vezes era um povo, uma época, um mito." (MEYER, 1986, 14). Trata-se do nascimento da projeção fantasmagórica do autor enquanto figura alegórica - figura pública (e coletiva) que é um outro de si mesmo, em sua errância ou travessia.

\section{Referência bibliográfica}

BARTHES, Roland. A morte do autor. In: BARTHES, Roland. O rumor da lingua. Trad. António Gonçalves. Lisboa: Ediçōes 70, 1987, p. $49-53$.

CAMPOS, Augusto e Haroldo de. Panaroma do Finnegans Wake. São Paulo: Perspectiva, 1971.

CANDIDO, Antonio. 0 homem dos avessos. In: CANDIDO, Antonio. Tese e antítese. 3. ed. São Paulo: Companhia Editora Nacional, 1978, 119-139.

EULALIO, Alexandre. Rocha no meio do caminho. In: EULALIO, Alexandre. Livro involuntário. Rio de Janeiro: UFRJ, 1993, p.299-301.

FANON, Frantz. Os condenados da terra. 2. ed. Trad. José L. de Melo. Rio de Janeiro: Civilização Brasileira, 1979.

MEYER, Augusto. $O$ autor, esse fantasma. In: MEYER, Augusto. Textos críticos. Org. João Alexandre Barbosa. São Paulo: Perspectiva/INL, 1986, p.11-14.

MIGUEL, Antônio Carlos. Riverão Sussuarana (Resenha). Encontros com a Civilização Brasileira. Rio de Janeiro, n 15, p. 212-215, set. 1979.

RETAMAR, Roberto Fernández. Caliban e outros ensaios. Trad. Maria Helena M. Hiriart e Emir Sader. São Paulo: Busca Vida, 1988.

REZENDE, Sidney (Org.). Ideário de Glauber Rocba. Rio de Janeiro: Philobiblion, 1986.

ROCHA, Glauber. Revolução do Cinema Novo. Rio de Janeiro: Alhambra/Embrafilme, 1981. $2^{\mathrm{a}}$ ed: São Paulo: Cosac Naify, 2004.

ROCHA, Glauber. Riverão Sussuarana. Rio de Janeiro: Record, 1978.

ROSA, João Guimarães. Estas estórias. $2^{\mathrm{a}}$ ed. Rio de Janeiro: José Olympio, 1976.

ROSA, João Guimarães. Grande sertão: veredas. $12^{\mathrm{a}}$ ed. Rio de Janeiro: José Olympio, 1977.

SHAKESPEARE, William. The Tempest. In: SHAKESPEARE, William. Longmans' School Shakespeare. London: Longmans, Green and Co. Ltd., 1931, p.456-507. 